\title{
Plastic growth of the herbivorous reef fish Sparisoma viride: field evidence for a trade-off between growth and reproduction
}

\author{
J. M. van Rooij, J. H. Bruggemann, J. J. Videler, A. M. Breeman \\ Department of Marine Biology, University of Groningen, PO Box 14, 9750 AA Haren, The Netherlands
}

\begin{abstract}
The growth of different life phases and social categories of the protogynous parrotfish Sparisoma viride was studied on a fringing reef on Bonaire (Netherlands Antilles) using mark-recapture procedures and by taking repeated stereographic measurements of free-swimming fish. Weightgrowth was best described by the Pütter/von Bertalanffy growth equation for all categories, allowing comparison of specific growth rates ( $\mathrm{d} W / W \mathrm{~d} t$ ) using analysis of covariance with $W^{-1 / 3}$ as the covariate. Growth was retarded by Peterson discs, but no effect of fin clips was detected. Adjusted for size differences, growth of juveniles was fastest, followed by sexually inactive terminal phase (TP) males living in groups. Initial phase (IP) females and territorial TP males (spawning daily) showed the lowest growth rates. Growth rate of territoria] males was negatively correlated with their average spawning rate. All adult categories showed seasonal variations in growth, the highest rates occurring in the warmest season (August to October). A possible effect of depth on growth is confounded by differences in social and reproductive status. Growth of group TP males showed a weak positive correlation with their condition. Gross growth efficiencies were estimated by combining data on growth and body composition with previously published data on food intake and assimilation. Growth efficiency is highest for protein, ranging from $50.6 \%$ of food intake for juveniles to $0.12 \%$ for territorial males. Corresponding values are 6.25 to $0.01 \%$ for ash-free dry weight and 7.9 to $0.01 \%$ for energy. The high abundance of small, sexually inactive group TP males (early sex-changers) in our $S$. viride population is related to their fast growth. We suggest that these 'bachelors' trade growth against current reproduction and thereby enhance their chance to acquire the status of a territorial male with high reproductive success. Insight into intraspecific variation in growth improves the accuracy of trophodynamic models and increases our understanding of complex life history patterns in fish.
\end{abstract}

KEY WORDS: Growth rate - Intraspecific variability - Growth efficiency - Herbivorous reef fish - Tradeoff - Reproduction - Life history tactics - Sparisoma viride

\section{INTRODUCTION}

Parrotfish (family Scaridae) form an important group of herbivores on coral reefs and play a major role in the transfer of energy from primary producers to higher trophic levels (Choat 1991). Scarids seem to be able to grow at rates comparable to or even higher than those of carnivorous reef fish, despite the relatively low nitrogen content of their diet (Munro \& Williams 1985 , Russ \& St. John 1988). However, published data on the growth of herbivorous reef fish are scarce (Horn 1989) and cannot be generalized because inter- and intra- specific variation in growth is likely to occur. Weatherly \& Gill (1987) stress the plastic nature of fish growth, which may vary considerably with varying food supply, temperature and population density. Intraspecific variation in growth of coral reef fish has been demonstrated frequently (e.g. Warner \& Downs 1977, Thresher 1983, Warner 1984, Jones 1986, Gladstone \& Westoby 1988, Clarke 1992) but has rarely been taken into account in trophodynamic studies. In a recent trophodynamic model of fish production on a reef-tract at the Great Barrier Reef, Polunin \& Klumpp (1992) estimate the gross growth efficiency of grazing 
fish species to be $1 \%$. This estimate was based on measurements of adult growth rates in 2 pomacentrid and 2 scarid species. A much cruder estimate was used in an earlier model by Polovina (1984), where he used an average growth efficiency (referred to as 'ecological efficiency') of $16 \%$ for all reef fish (comprising several trophic levels). Due to a lack of data, inter- and intraspecific variability was neglected in these models, which shows the urgent need for more quantitative data on growth rates and efficiencies of (herbivorous) coral reef fish.

Growth is also an important factor in the life history of fish. A fundamental concept in life history theory is that of trade-offs, which exist if a fitness benefit due to a change in one life history trait is linked to a cost incurred by a change in another (Stearns 1992). Tradeoffs are expected when an organism can acquire only a limited amount of energy that has to be divided between competing physiological processes. A well known example is the trade-off between growth and reproduction, which has been shown to exist in trees, barnacles and fish (see review in Stearns 1992). Considering that fish growth is usually indeterminate and that mortality and fecundity tend to be highly size specific (Wootton 1990), it is apparent that an individual's expected lifetime reproductive success strongly depends on its growth pattern throughout life. In a variable environment a flexible growth pattern seems highly adaptive. Evidence for such flexibility in reef fish, involving a trade-off between growth and reproduction, is provided by Warner \& Downs (1977) for the striped parrotfish Scarus iserti, and by Warner (1984) for initial phase males of the blue-headed wrasse Thalassoma bifasciatum. The work on these protogynous reef fish shows that this trade-off may play an important role in alternative male mating tactics. In both studies some males were found to invest in growth at the cost of current reproduction, thus increasing the probability of attaining a successful dominant male status and, hence, their future prospects. However, a trade-off between growth and reproduction is not always found, as illustrated by the field studies of Schulz \& Warner $(1989,1991)$ on female T. bifasciatum. A complication in such studies is uncontrolled variation in resource abundance. Fish with access to better resources may show both increased growth and a larger reproductive effort.

The stoplight parrotfish Sparisoma viride (Bonnaterre) is a common herbivore on Caribbean coral reefs. It is a protogynous hermaphrodite (Reinboth 1968), in which 3 life phases are distinguished: juveniles ( $\mathrm{JU},<15 \mathrm{~cm}$ ), initial phase (IP) adults (mostly female but some may be male) and terminal phase (TP) males (derived from IP females through sex and colour change). The social and mating system of $S$. viride at our study site is described in detail elsewhere (J. M. van Rooij, J. J. Videler \& F. Kroon unpubl.). Two main adult social categories are distinguished, territorial and group fish, which are confined to different parts of the reef. Territorial fish occupy most of the deeper reef between 3 and $25 \mathrm{~m}$, where single TP males (TTP) share their territory with 1 to 13 IP females (TIP) with whom they spawn daily. Group fish (GTP and GIP) share common home ranges in the shallowest parts of the reef $(<3 \mathrm{~m})$, where no sexual activity occurs. GTP hardly spawn at all, whereas GIP may spawn as frequently as TIP ( 1 to 2 spawnings $\mathrm{d}^{-1}$ ) at the deeper reef. An intriguing feature of this system is the high abundance of relatively small, sexually inactive GTP or 'bachelors'. If these fish had stayed IP females (a possible option, since the timing of sex change appears to be flexible), they would have gained higher reproductive success. Possibly, as proposed by Warner (1991), bachelors follow an alternative life history tactic, sacrificing current reproductive output for better future prospects. This goal could be realized if they attain higher growth rates than equally sized IP females and, thus, have a better chance to attain the successful territorial male status.

Supply, intake and assimilation of food by Sparisoma viride at our study site have been studied by Bruggemann et al. (1994a, b). Epilithic algal turfs, crustose corallines and endolithic algae, the main food sources, are not distributed evenly over the reef and differ in quality (Bruggemann et al. 1994a). Food intake and assimilation is further affected by the skeletal density of the substratum. Due to a higher relative abundance of high yield food patches on the deeper reef, territorial fish have been shown to ingest and assimilate larger amounts of food than group fish on the shallow reef (Bruggemann et al. 1994b). Considering the differences in food uptake and reproductive effort, members of different social categories and life phases (henceforth simply referred to as categories) can be expected to show differential growth. Because the average food uptake of the different categories is known, we can determine whether growth differences can actually be ascribed to tactical reallocation of energy, rather than to variations in food availability or quality.

Although seasonal fluctuations in temperature and daylength are small, and despite the lack of a distinct spawning season, Sparisoma viride shows seasonal variation in condition (van Rooij et al. 1995). Fish were in poorest condition in the season with longest days (May to July), while their condition was best when water temperature was highest (around October). Likewise, growth can be expected to vary seasonally and may further be affected by condition itself. However, changes in condition (changes in weight without simultaneous change in length) and in growth do not have to be coupled. Variations in condition can be 
expected to reflect short-term shifts in the balance of energy uptake and expenditure, whereas growth can only be realised if the balance remains positive over prolonged periods.

This study is part of a larger project addressing the role of Sparisoma viride in the trophodynamics of the fringing reef of Bonaire (Netherlands Antilles). Our main objective here is to compare growth rates and efficiencies of different $S$. viride categories and to investigate the effects of season, depth of the home range, and condition. Furthermore, possible complications due to size-related growth differences or resulting from different measuring and tagging methods will be taken into account.

\section{MATERIAL AND METHODS}

Study site. The study was carried out at a $250 \mathrm{~m}$ wide stretch of the fringing reef off the ecological centre Karpata on the leeward coast of Bonaire $\left(12^{\circ} \mathrm{N}, 68^{\circ} \mathrm{W}\right)$ between March 1987 and October 1991. The study site is described in more detail elsewhere (van Rooij et al. unpubl.). Mean monthly water temperatures between 1 and $10 \mathrm{~m}$ depth fluctuated between 25.8 and $29.8^{\circ} \mathrm{C}$ with the highest temperatures in September or October and the minima in February. Daylength varies between a winter minimum of $11 \mathrm{~h} 25$ min and a summer maximum of 12 h 51 min (see Fig. 1 in van Rooij et al. 1995).

Fish capture, measuring and tagging. Fish were either captured at night, using handnets and an anaesthetic (quinaldine, 'Aquavet Seaquin' water-base collection anaesthetic), or by day after encirclement with a seine net $(84 \mathrm{~m}$ long, $10 \mathrm{~m}$ deep, $5 \mathrm{~cm}$ stretched mesh). Before measurement, larger fish were anaesthetized in seawater containing $0.1 \mathrm{ml} \mathrm{l}^{-1}$ quinaldine. Water was forced out of the gills and beak, and the fish were dried in a humid towel before weighing them to the nearest gram on a triple beam balance. Fork length ( $F L$, from tip of jaw with closed mouth to tip of shortest median ray of tail fin) was measured on a board with an upright edge and noted to the nearest $\mathrm{mm}$. Fish $<10 \mathrm{~cm} F L$ were weighed on an analytical balance to the nearest $\mathrm{mg}$, and length was measured in tenths of a mm using vernier callipers. These small fish were not narcotized but measured in a sealed plastic bag with a little seawater. All fish were measured after 1 night in the absence of food and after excretion of a compact faecal pellet, yielding a weight with empty gut.

TP males could be individually recognized by distinct yellow scale patterns at the caudal peduncle. Recognition of TTP males was further facilitated by their site fidelity. However, due to the high density and turnover of GTP, individual recognition over pro- longed periods proved to be difficult. Most GTP males were therefore marked with 1 to 4 small fin clips in the median fins. IP fish could not be distinguished by natural markings and were tagged with either fin clips in the median fins, Peterson discs, or anchor tags. Tags were applied just below the dorsal fin with a tagging gun (tags type FD-67 and FD67F and Mark II SS tagging gun from Floy Tag \& Manufacturing Inc., Seattle). Most Peterson disks were lost within a few weeks, leaving distinct wounds, and were therefore no longer used after the first trials. Anchor tags lasted for 3 to $9 \mathrm{mo}$ and left no visible wounds after loss. Clipped fins recovered within 3 to 6 mo. Recaptured fish were provided with a new tag if the old one had disappeared, so that a number of IP fish could be followed over a period of more than 1 yr. A few fish were not brought ashore but were tagged underwater; only FL could be measured in these cases. Fish caught at night were followed after release early the next morning in order to determine the location of their home range. Subsequent observations were carried out to assess their social and reproductive status.

Growth measurements. Most data on the growth of IP and GTP fish were obtained by tag-recapture experiments. TTP males easily lose their territorial status following capture and release. Therefore, we also used stereo photography to measure FL of free-swimming fish repeatedly over a 20 mo period. The method is described by van Rooij \& Videler (1995) and yields an accuracy of $\pm 10 \%$ for single exposures, which is improved to $\pm 3 \%$ by averaging 3 or more replicate measurements. JU fish were rarely relocated after tagging, and their growth was measured in captivity. They were kept in a natural dark/light regime, either in a 951 tub ( $2 \mathrm{fish}<2 \mathrm{~cm}$ ) or in a large circular tank ( $2 \mathrm{~m}$ diameter, $0.8 \mathrm{~m}$ deep, 3 fish of 6 to $10 \mathrm{~cm}$ ). The tanks were continuously flushed with fresh seawater. The bottom was covered with fine and coarse coral rubble covered with algal turfs, which was collected daily from the reef between 1 and $7 \mathrm{~m}$ depth. Some live gorgonians and small coral heads were placed in the tanks as well.

Adult fish were usually measured at 1 to $4 \mathrm{mo}$ intervals, but also at longer intervals. Measurements obtained in 1 to 4 mo intervals were classified in 4 seasons (January to April, April to July, August to October and October to December) to allow a comparison of growth in different seasons.

Calculation of growth. Growth has been calculated in length units as well as in weight units. Lengths obtained by stereo photography or by direct measurement underwater (no weight measured) were converted to weights using the equation $W_{\text {pred }}=9.115 \times$ $F L^{3.140}$ (predicted weight $W_{\text {pred }}$ in $\mathrm{g}, F L$ in $\mathrm{mm}$ ), as obtained by geometric mean regression (cf. Ricker 1984) for fish with empty guts by van Rooij et al. (1995). 
This equation was also used to calculate a condition factor $(C F)$ for fish whose actual weight $\left(W_{\text {meas }}\right)$ was measured: $\left.C F=W_{\text {meas }} / W_{\text {pred }}\right)$.

Growth of fish is size-dependent and follows a sigmoid curve when weight is plotted against time or age. However, growth during a limited time span can usually be described adequately by the exponential function: $M_{t}=$ $M_{0} \times \mathrm{e}^{G \times t}$; where $M_{t}$ is size (either length or weight) at time $t_{1} M_{0}$ is the initial size $(t=0)$, e is the base of the natural logarithm (ln), and $G$ is the instantaneous relative growth rate, also referred to as the specific growth rate (Ricker 1979). We calculated $G$ as: $G=\left(\ln M_{2}-\ln M_{1}\right) /$ $\left(t_{2}-t_{1}\right)=\mathrm{d} \ln M / \mathrm{d} t=\mathrm{d} M /(M \times \mathrm{d} t) ;$ with $M$ measured in $\mathrm{mm} F L$ or in $\mathrm{g}$ fresh weight and time in days.

If stereo measurements were involved in an estimate of $G$, a different procedure was followed to calculate seasonal and yearly specific growth rates. For seasonal growth rates, replicate stereo measurements at a single date were averaged to obtain the most accurate estimate of $M$. In 18 out of 65 cases the stereo measurements of a TTP male at a single date showed a large variation and were therefore averaged with those of the next or preceding date. Yearly growth rates of ITP (which were measured by stereo photography exclusively) were determined by regression of all $\ln M$ data on time, the slope of which yielded a single estimate of $G$ for each male. This way, $G$ reflects an average that is weighted for the number of stereo exposures at each date (as opposed to the unweighted seasonal rates). Likewise, when stereo estimates for IP and GTP were obtained on 1 or more successive dates in some interval, a single estimate of the yearly growth rate for the entire interval was calculated from the regression of $\ln M$ over time. For specific growth rates based on direct length or weight measurements, no distinction. between seasonal and yearly rates was made.

Comparison of growth. To compare the growth of different Sparisoma viride categories (each comprising a range of sizes), some model has to be used that takes into account the decrease of $G$ with increasing age (resulting in the sigmoid lifetime growth curve). The Pütter/von Bertalanffy growth (henceforth referred to as VBG) equation is often used by fish biologists but has also been criticized, and other equations have been used with success as well (Ricker 1979). We, therefore, fitted the differential forms of 5 equations given by Ricker (1979; the Logistic, VBG, Gompertz, Johnson, and Richards growth curves) to the lengthand weight-growth data of all $S$. viride categories. To that purpose the specific growth rates $(G)$ of all fish belonging to the same category were plotted against their geometric mean size $\left(M_{\mathrm{gm}}=\mathrm{e}^{\left(\ln M_{0}+\ln M_{t}\right) / 2}\right.$, where $M_{0}$ and $M_{t}$ denote the initial and final size of the fish over time interval $t$ ). Next the data were fitted by linear regression of $G$ on (1) $M_{\mathrm{gm}}$ (Logistic), (2) on $W_{\mathrm{gm}}{ }^{-1 / 3}$
(VBG in weight) or $F L_{\mathrm{gm}^{-1}}$ (VBG in length), and (3) on In $M_{\mathrm{gm}}$ (Gompertz); (4) by linear regression of $\sqrt{G}$ on $\ln M_{\mathrm{gm}}$ (Johnson); and (5) by nonlinear regression of $G$ on $M_{\mathrm{gm}}$ (Richards). All growth equations yield an upper asymptote $M_{\infty}$ and for each an integral form can be derived that predicts $M$ as a function of time or age (see Ricker 1979).

We will only present the parameter estimates for those length- and weight-growth equations that yielded the best fits (i.e. the largest $R^{2}$ values). Because for all categories the best fits were obtained by the VBG equation for weight-growth, growth rates were compared statistically using analysis of covariance (ANCOVA) with $W_{\mathrm{gm}}{ }^{-1 / 3}$ as the covariate. All interaction terms were included in the designs but will only be mentioned when significant. Equality of slopes tests (cf. Sokal \& Rohlf 1981) were performed by testing the interaction term: Covariate $\times$ Factor $1(\times$ Factor $2 \times \ldots$ )

Most statistical tests were performed with the cumputer package SPSS/PC+ (version 4.01, 1990). The outcome of a test was considered statistically significant if the 'Type I' error did not exceed 0.05. Linear and nonlinear reyressions were performed with Stutgraphics (version 2.6, 1986).

Body composition and energy content. To allow conversion of growth in wet weight units to ash-free dry weight (AFDW), protein, and energy, the body composition and energy content of whole fish with empty guts was determined. Fish wet weight and $F L$ were measured as before. The gonads were dissected immediately after a fish was killed, and a gonadosomatic index (GSI) was calculated as (fresh gonad weight $\times 100 \%) /($ fish wet weight). Dry weight (DW) was determined after drying at $60^{\circ} \mathrm{C}$ until constant weight. Dried whole fish (plus gonads) were homogenized by grinding in a centrifugal mill (Retsch). Triplicate subsamples ( 0.7 to $5 \mathrm{~g} \mathrm{DW}$, depending on fish size) were ashed for $3.5 \mathrm{~h}$ at $500^{\circ} \mathrm{C}$ to determine AFDW. Lipid content was determined as the decrease in DW of 6 subsamples ( 0.7 to $5 \mathrm{~g}$ initial DW) after fat extraction in petroleum ether for $8 \mathrm{~h}$. Organic nitrogen content of 5 subsamples ( $0.2 \mathrm{~g} \mathrm{DW}$ ) was determined by the Kjeldahl procedure and multiplied by 6.25 to obtain the protein content (Elliott 1976). The energy content of triplicate subsamples ( $1 \mathrm{~g}$ DW) was determined using an adiabatic bomb calorimeter (Gallenkamp). We checked for endothermy due to the presence of $\mathrm{CaCO}_{3}$ (Paine 1966) by combusting mixtures of $25 \%$ ash (fractions obtained in the AFDW determinations) and $75 \%$ benzoic acid. The average energy content ( $\mathrm{g}^{-1}$ AFDW) of these mixtures did not differ significantly from that of pure benzoic acid $\left(F_{1,12}=1.56, \mathrm{p}=0.235\right)$, so no correction for endothermy was made.

Because we wanted to kill as few fish as possible, only 6 individuals were sacrificed for the determina- 
tions ( 2 juveniles, 3 IP females, 1 TP male). For the smallest JU fish we could only determine the energy content (due to its small weight). It was combusted in a non-adiabatic microbomb calorimeter (Phillipson type, as described by Prus 1975), yielding a single energy content (plus ash content). As a check of the accuracy of the determinations, the energy contents of the 5 largest fish obtained by bomb calorimetry were compared with those calculated from the protein $(23.6 \mathrm{~kJ}$ $\mathrm{g}^{-1}$ ) and lipid (39.5 $\mathrm{kJ} \mathrm{g}^{-1}$ ) content of the fish (assuming the contribution of carbohydrates can be ignored; cf. Elliott 1976).

Growth efficiency. We calculated 2 measures of gross growth efficiency (cf. Wootton 1990):

$$
\begin{aligned}
& K_{1}=(\text { growth } \times 100 \%) /(\text { intake }), \text { and } \\
& K_{2}=(\text { growth } \times 100 \%) /(\text { assimilation }),
\end{aligned}
$$

using the growth data presented here and the data on food intake and assimilation of Sparisoma viride in our study area that were obtained (largely in the same period) by Bruggemann et al. (1994a, b).

Daily somatic production of fish (in fresh weight units) was calculated from the differential form of the VBG equation for weight:

$$
\mathrm{d} W / \mathrm{d} t=\mathrm{c}_{2} \times W^{2 / 3}-\mathrm{c}_{1} \times W\left(\text { with } \mathrm{c}_{2}=\mathrm{c}_{1} \times W_{\infty}^{-1 / 3}\right)
$$

where $C_{1}$ and $C_{2}$ are the parameter estimates for the VBG fits to the weight-growth data. Daily production was calculated for a $10 \mathrm{~cm}$ JU, a $20 \mathrm{~cm}$ IP (using the JU growth parameters), a $30 \mathrm{~cm}$ IP and a $40 \mathrm{~cm} \mathrm{TP}$, with separate estimates for GTP and TTP males. Production was converted from fresh weight units to AFDW, protein and energy units using the body composition data of the fish of nearest corresponding size. Daily food intake and assimilation of these size classes was taken from Table 7 in Bruggemann et al. (1994b). Their estimates were obtained by a combination of laboratory experiments and field observations. Food intake was calculated from the yield per bite and the daily number of bites on different food and substrate types (both in relation to fish size, life phase and foraging depth), and from the biochemical composition of food types. Assimilation efficiency was determined by quantitative measurements of food consumed and faeces produced by fish that were held in captivity and fed natural diets. See Bruggemann et al. (1994a, b) for further details.

\section{RESULTS}

\section{Fits to the growth equations}

Because most larger IP fish were observed to spawn with TP males or to release eggs upon examination, and since IP males were rare at our study site (van
Rooij et al. unpubl.), the larger IP fish are assumed to be mature females. The 4 smallest IP fish $(<200 \mathrm{~g})$ were never observed to spawn or to release eggs and were, therefore, grouped with juveniles in the growth analyses. Within the IP category, no growth differences could be detected between territorial and group fish $\left(F_{1,23}=0.00, \mathrm{p}=0.986\right)$, so they are treated as a single category. Therefore, all growth models have been fitted to 4 Sparisoma viride categories: JU, IP, TTP and GTP.

The VBG equation yielded the best fits to the yearly specific weight-growth rates of $\mathrm{JU}\left(\mathrm{R}^{2}=95 \%, \mathrm{n}=11\right)$ and IP fish $\left(\mathrm{R}^{2}=51.9 \%, \mathrm{n}=26\right)$ and fits as good as the Gompertz and Richards models for GTP $\left(\mathrm{R}^{2}=47.1 \%, \mathrm{n}\right.$ $=56)$ and TTP $\left(\mathrm{R}^{2}=4 \%, \mathrm{n}=15\right)$ males. Length-growth was best described by the VBG model for IP $\left(R^{2}=\right.$ $50.5 \%)$ and TTP $\left(\mathrm{R}^{2}=2.4 \%\right)$, but for JU the Johnson $\left(R^{2}=92.7 \%\right)$ and for GTP the Logistic $\left(R^{2}=40.4 \%\right)$ equation yielded the best fits (same sample sizes). The parameter estimates and the (differential and integral forms of the) equations are summarized in Table 1. Only the regressions for TTP males were not statistically significant. This can be ascribed, however, to the small slope of the regression lines (not significantly deviating from zero), rather than to a bad fit (with little variation in the dependent variable, not much can be explained by the independent variable; compare Fig. $1 \mathrm{~A}$ to $\mathrm{C}$ ).

\section{Comparison of growth}

Effect of measuring and tagging methods on growth

Most IP fish that were tagged with a Peterson disc soon lost their tag, which left clearly visible wounds. At first recapture, the wounds were nearly healed and the fish were provided with an anchor tag. Growth of the smaller fish with Peterson discs was seriously retarded, resulting in a significantly less steep slope than the one found for IP fish tagged otherwise (Fig. 1A; equality of slopes test: $F_{1,28}=5.24, p=0.030$ j. Therefore, the growth rates of the fish with Peterson discs were omitted from all other analyses. The stereo photography data show a somewhat greater variability than the growth rates obtained by direct measurement (Bartlett-Box test: $\mathrm{p}=0.078$ ), reflecting the lower accuracy. However, the yearly specific growth rates of IP fish measured by stereo photography do not deviate from those determined by mark-recapture $\left(F_{1,23}=0.02\right.$, $\mathrm{p}=0.903$ ).

Likewise, both measuring methods yield comparable yearly growth rates for GTP (Fig. $1 B_{;} F_{1,53}=1.30, \mathrm{p}=$ 0.260 ). To check whether growth was affected by fin clipping we compared the growth of group males 
tagged with a different number of finclips. GTP without finclips showed slower growth rates than the tagged males $\left(F_{4} 48=3.27, \mathrm{p}=0.019\right)$ but were mainly measured in the cooler parts of the year (with retarded growth, see below). In a full factorial 2-way ANCOVA design with season as second factor, the number of fin

Table 1. Sparisoma viride. Parameter estimates and growth equations (differential and integral forms) that yielded the best fits to the yearly specific weight-and length-growth rates of juveniles (JU), initial phase fish (IP), group and territorial terminal phase (GTP and TTP respectively) males

\section{Pütter/von Bertalanffy growth (VBG) equations: \\ For weight \\ Differential form: $G=\mathrm{d} W_{t} /\left(W_{t} \times \mathrm{d}_{t}\right)=\left(\mathrm{C}_{2} \times W_{t}^{-1 / 3}\right)-\mathrm{C}_{1 i}$ \\ Integral form: $\quad W_{t}=\left[c_{2} / c_{1}-\left(c_{2} / c_{1}-W_{0}^{1 / 3}\right) \times e^{-c_{1} \times 4 / 3}\right]^{3}$ \\ where $W_{t}$ is weight at time $t$ (in $\left.d\right),\left(c_{1} / 3\right.$ is usually referred to as $K),\left(c_{2} / c_{1}\right)^{3}$ is asymptotic weight $W_{\infty}$ and $W_{0}$ is set at the predicted weight of the smallest fish belonging to each category.

\begin{tabular}{lcccr} 
& $c_{1}$ & $c_{2}$ & $W_{0}$ & \multicolumn{1}{c}{$W_{m}$} \\
\hline JU & 0.0004191 & 0.0294462 & $8 \mathrm{mg}$ & $346844.0 \mathrm{~g}$ \\
IP & 0.0088305 & 0.0734930 & $200 \mathrm{~g}$ & $576.5 \mathrm{~g}$ \\
TTP & 0.0009305 & 0.0104586 & $630 \mathrm{~g}$ & $1419.9 \mathrm{~g}$ \\
GTP & 0.0029965 & 0.0368162 & $200 \mathrm{~g}$ & $1854.6 \mathrm{~g}$
\end{tabular}

\section{For length}

Differential form: $G=\mathrm{d} L_{t} /\left(L_{t} \times \mathrm{dt}\right)=\left(\mathrm{C}_{2} / L_{t}\right)-\mathrm{C}_{1}$ i

Integral form: $\quad L_{t}=c_{2} / c_{1}-\left(c_{2} / c_{1}-L_{0}\right) \times e^{-c_{1} \times v_{3}}$

where $L_{t}$ is length at time $t$ (in $\left.d\right)_{1}\left(c_{1}\right.$ is usually referred to as $K)_{1} C_{2} / C_{1}$ is asymptotic length $L_{s, a}$ and $L_{0}$ is set at the length of the smallest fish belonging to each category.

\begin{tabular}{lcccc} 
& $c_{1}$ & $c_{2}$ & $L_{0}$ & $L_{\infty}$ \\
\hline IP & 0.0029633 & 0.9042470 & $215 \mathrm{~mm}$ & $305.2 \mathrm{~mm}$ \\
TTP & 0.0002089 & 0.0916488 & $310 \mathrm{~mm}$ & $438.7 \mathrm{~mm}$
\end{tabular}

Johnson equation (length growth JU):

Differential form: $G=\mathrm{d} L_{t} /\left(L_{t} \times \mathrm{d} t\right)=c_{1} \times\left(\ln L_{\infty}-\ln L_{t}\right)^{2}$;

Integral form: $\quad L_{t}=L_{\infty} \times \mathrm{e}^{\left.-1 / c_{1} \times\left\{t-t_{0}\right)\right\}}$

$$
t_{0}=1 /\left[c_{1} \times\left(\ln L_{0}-\ln L_{\infty}\right)\right]
$$

where $t_{0}$ is the point at which the curve meets the time axis, and with $L_{n} L_{\infty}$ and $L_{0}$ as before.

\begin{tabular}{cccc} 
& $c_{1}$ & $L_{0}$ & $L_{\infty}$ \\
\hline $\mathrm{JU}$ & 0.0021071 & $18 \mathrm{~mm}$ & $409.1 \mathrm{~mm}$
\end{tabular}

Logistic equation (length growth GTP males):

Differential form: $G=\mathrm{d} L_{t} /\left(L_{l} \times \mathrm{d} t\right)=\mathrm{C}_{\mathrm{y}} \times\left(L_{\infty}-L_{t}\right) / L_{\infty}$;

Integral form: $\quad L_{t}=L_{\infty} /\left[1+\mathrm{e}^{-C_{1} \times(t-i w)}\right]_{i}$

$$
t_{0}=\left(1 / c_{1}\right) \times \ln \left[\left(L_{\infty}-L_{0}\right) / L_{0}\right]
$$

where $t_{0}$ is the inflection point of the integral curve, and with $L_{1}, L_{\infty}$ and $L_{0}$ as before.

\begin{tabular}{cccc} 
& $c_{1}$ & $L_{0}$ & $L_{\infty}$ \\
\hline GTP & 0.0020809 & $215 \mathrm{~mm}$ & $388.3 \mathrm{~mm}$
\end{tabular}

clips (varying from 1 to 4 ) had no significant effect on growth $\left(F_{3,33}=0.73, \mathrm{p}=0.540\right.$, only the seasons May to July and August to October included).

Effect of sexual activity on growth of territorial males

All growth data of TTP males were obtained by stereo photography and only 1 yearly specific growth rate was obtained per male (Fig. 1C). All 15 TTP males were regularly observed during the daily spawning period and their sexual activity was quantified by calculating an average spawning rate, as described in van Rooij et al. (unpubl.). The spawning rate gives the
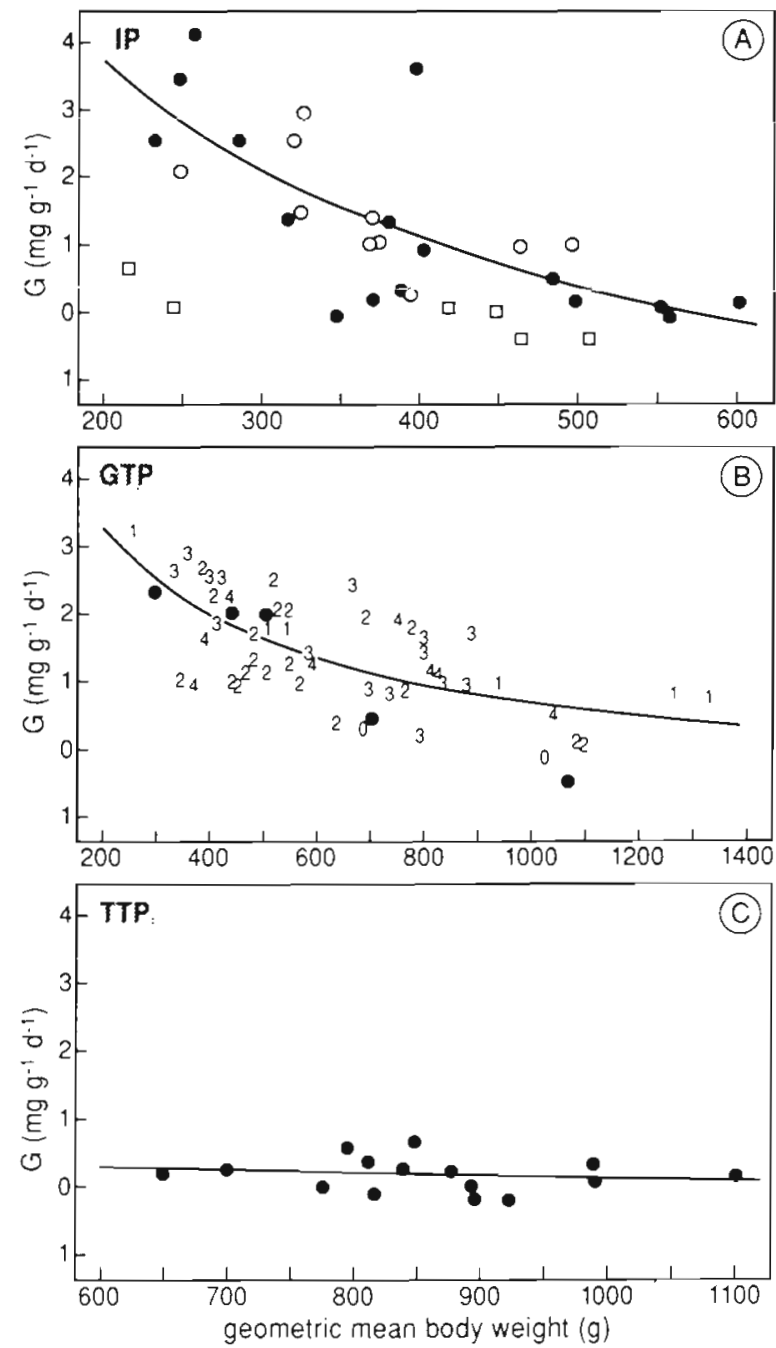

Fig. 1. Sparisoma viride. Yearly specific growth rates $(G$ in $\mathrm{mg}$ $\mathrm{g}^{-1} \mathrm{~d}^{-1}$ ) vs geometric mean weight. (A) Initial phase (IP) fish $>200 \mathrm{~g}$; (B) group terminal phase (GTP) males; (C) territorial (TTP) males. (-) Stereographic measurements; (O) markrecapture measurements; (D) IP fish tagged with a Peterson disc. Numbers $(0$ to 4 ): number of fin clips applied to GTP fish. Lines represent von Bertalanffy fits 
average daily spawning frequency, calculated over an individual's entire residence time, which spanned more than a year for most TTP males. To investigate the effect of average sexual activity, the residuals of the fit in Fig. $1 C$ were regressed upon the male's spawning rates (varying from 0 for 2 recently settled males to 11.3 for the most successful TTP male). This regression yielded a negative correlation:

$$
\begin{aligned}
& \text { G-residual }=-2.92 \times 10^{-5} \times \text { Spawning rate } \\
&+15.12 \times 10^{-5} \\
&\left(\mathrm{R}^{2}=20.81 \%, \mathrm{n}=15,1 \text {-tailed } \mathrm{p}=0.043\right) .
\end{aligned}
$$

A 1-tailed significance test is justified here because a negative correlation is expected a priori when growth is traded-off against reproductive effort. So, spawning appears to impede the growth of TTP males.

\section{Growth comparison between categories}

As apparent from Fig. 2, JU and GTP fish show relatively high growth rates compared to IP females and TTP males $\left(F_{3,103}=2.91, \mathrm{p}=0.038\right)$. Pairwise comparison of means suggests that only the growth of JU fish deviates significantly from the other 3 categories, but the differences are obscured by the relatively high variance in the JU data. When only the 3 adult categories are compared, growth of GTP males is significantly higher than that of both other categories $\left(F_{1,93}=\right.$ $20.14, \mathrm{p}<0.001$ for the comparison with IP, and $F_{1,93}=$ 8.22, $\mathrm{p}=0.005$ for the comparison with TTP). Further-

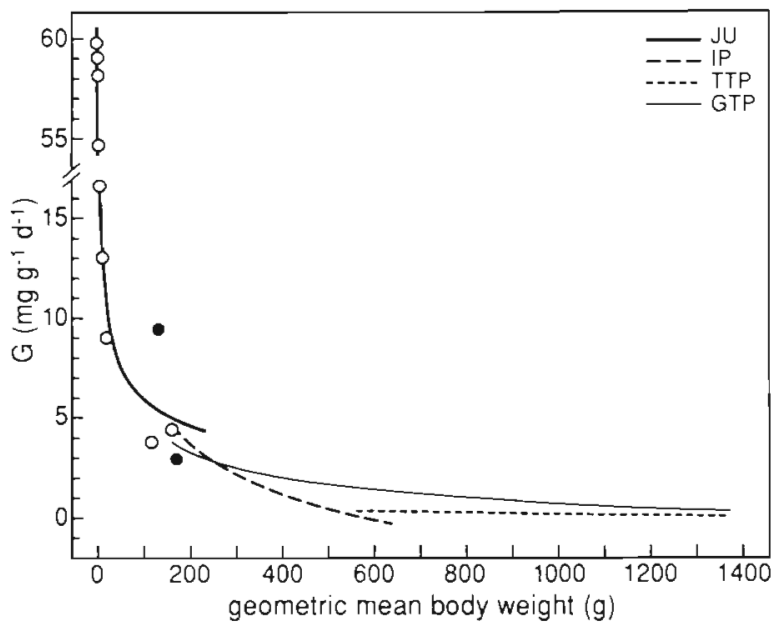

Fig. 2. Sparisoma viride. Comparison of von Bertalanffy fits to yearly specific growth rates (vs geometric mean weight) of juveniles [JU, including initial phase (IP) fish $<200 \mathrm{~g}$ ] and the 3 adult categories [IP, group and territorial terminal phase (GTP and TTP) males]. Actual rates shown for JU only (see Fig. 1 for adult rates). (@) Stereographic measurements; (O) mark-recapture measurements. Smallest 7 JU measured in captivity more, the growth of IP fish decreases more rapidly with increasing size than that of GTP males, as is apparent from a significantly steeper slope $\left(F_{1,91}=9.02, \mathrm{p}=0.003\right.$ for the comparison with GTP, and $F_{1,91}=2.70, \mathrm{p}=0.104$ for the comparison with TTP).

The individual JU growth rates are also plotted in Fig. 2. The rates of the 4 largest individuals were obtained from field measurements, 2 of these by stereo photography. Because of the small sample sizes, statistical comparison with the data obtained in captivity is not feasible. However, 3 of the 4 rates seem to fit in well. The fourth rate shows a relatively large deviation but was obtained by stereo measurement at the initial date and is, therefore, less accurate.

\section{Effect of home range depth on growth}

The effect of the depth range in which individuals resided could be tested for IP fish and for TTP males. IP fish in the 0 to $3 \mathrm{~m}$ and 3 to $6 \mathrm{~m}$ ranges tended to grow faster than IP fish in the 6 to $10 \mathrm{~m}$ zone, but the difference was not statistically significant $\left(F_{2.22}=0.72, \mathrm{p}=\right.$ $0.499)$. In contrast, growth of the TTP males tended to increase with depth $\left(F_{2,11}=0.79, \mathrm{p}=0.479\right)$.

\section{Seasonal effect on growth}

Comparison of seasonal specific growth rates (Fig. 3) shows increased rates in August to October, the warmest season, for all 3 adult categories, although only for GTP males is the effect of season significant (IP: $F_{4,33}=1.41, \mathrm{p}=0.251 ;$ TTP: $F_{4,43}=1.26, \mathrm{p}=0.299$; GTP: $F_{4.53}=4.05, \mathrm{p}=0.006$ ). Furthermore, GTP males showed somewhat retarded growth in the coldest season, January to April. Seven IP fish also grew relatively slowly in this season. However, 6 of those were tagged with a Peterson disc, which seems a more likely explanation for their retarded growth. Note that growth in the season in which fish showed the poorest condition (May to July; van Rooij et al. 1995) is intermediate, as are the rates calculated over periods longer than 4 mo.

\section{Effect of condition on growth}

To determine whether seasonal growth rates were affected by the condition of fish, the residual of the fits in Fig. 3A, B were regressed upon several condition indices of IP and GTP fish that were measured following capture. $C F$ at the beginning of each growthperiod $\left(C F_{t_{0}}\right), C F$ at the end $\left(C F_{t}\right)$, the average of the two $\left(C F_{\text {avg }}\right)$, and the difference $C F_{t}-C F_{t_{0}}(\mathrm{~d} C F)$ were used as indices of condition. No significant correlations 


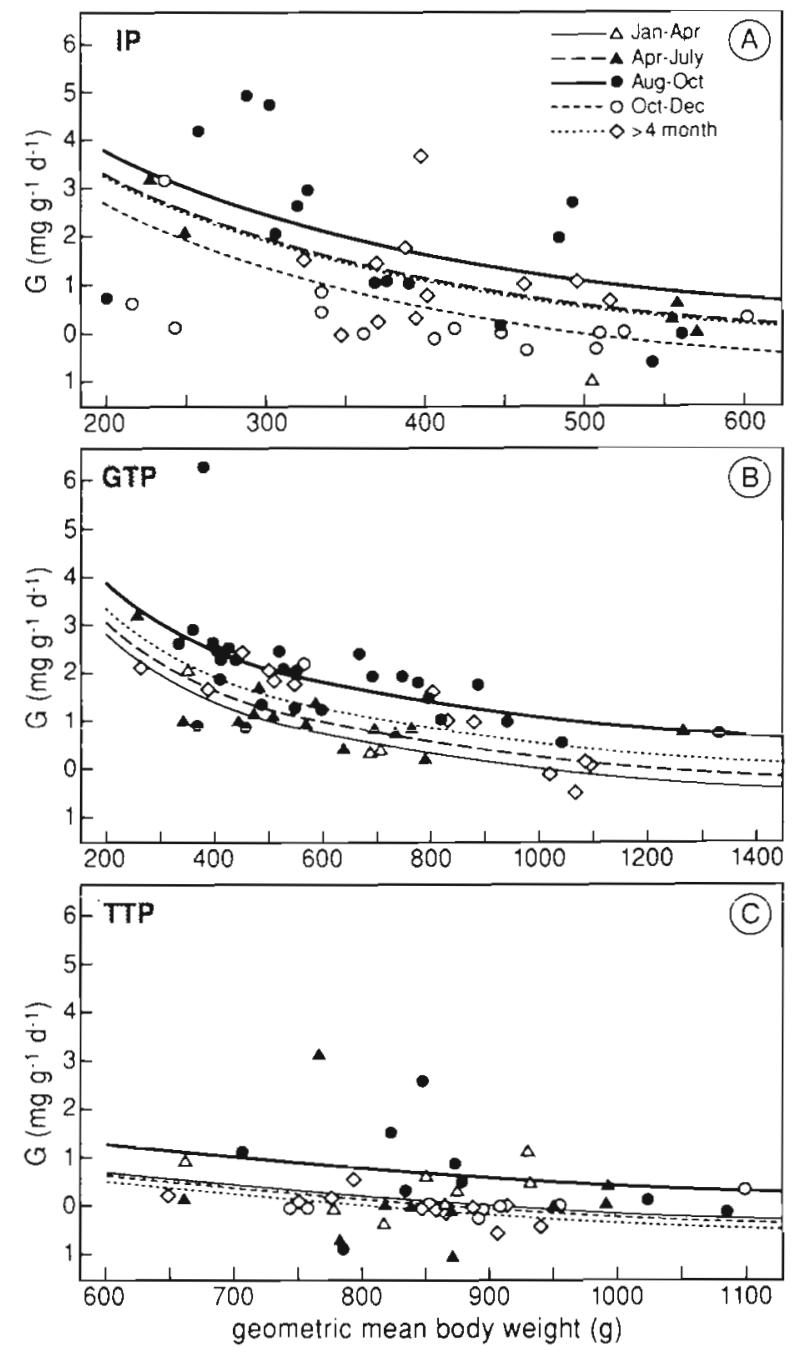

Fig. 3. Sparisoma viride. Seasonal specific growth rates $(G$ in mg $g^{-1} \mathrm{~d}^{-1}$ ) vs geometric mean weight, and von Bertalanffy fits obtained for (A) initial phase fish (IP, fitted lines for April to July and for periods $>4$ mo coincide; $n=1$ for January to April, so no fit), (B) group terminal phase males (GTP, $n=1$ for October to December, so no line fitted), and (C) territorial terminal phase males (TTP, fitted lines for October to December, January to April and April to July coincide)

were found for IP fish ( $p>0.32$ in all cases). For GTP males a positive correlation was found, for $C F_{t_{0}}\left(\mathrm{R}^{2}=\right.$ $12.8 \%, \mathrm{n}=43, \mathrm{p}=0.019)$, for $C F_{t}\left(\mathrm{R}^{2}=7.5 \%, \mathrm{n}=45, \mathrm{p}\right.$ $=0.068)$, and for $C F_{\text {avg }}\left(\mathrm{R}^{2}=12.2 \%, \mathrm{n}=43, \mathrm{p}=0.022\right)$. Apparently, GTP males that are in better condition grow at somewhat higher rates

\section{Body composition, energy content and growth efficiencies}

Comparison of body composition characteristics and size of the 6 dissected fish (Fig. 4) indicated that fish
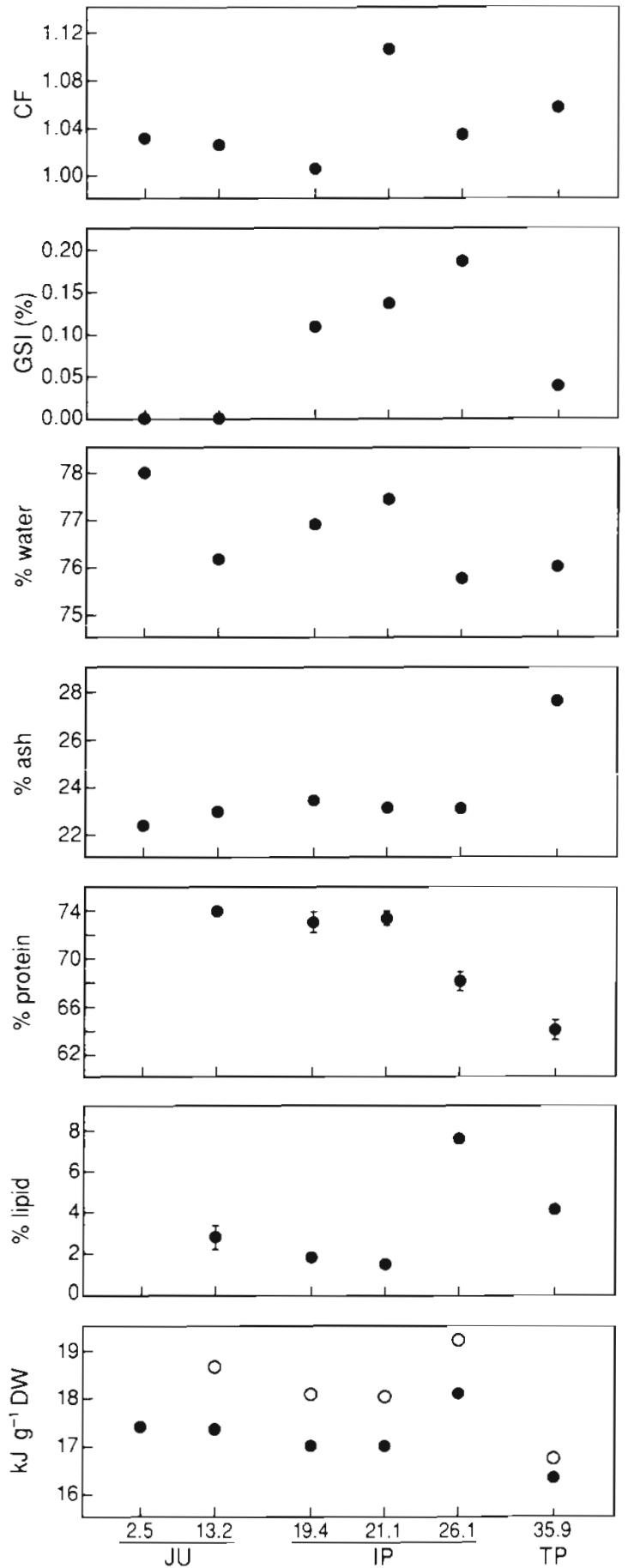

Fig. 4. Sparisoma viride. Body composition characteristics of 6 fish of different size [shown below $x$-axis in $\mathrm{cm}_{i} 2$ juveniles (JU), 3 initial phase (IP) and 1 terminal phase (TP) fish]. From top to bottom: condition factor (CF); gonadosomatic index (GSI, \% of fish wet weight, FWW); water content ( $\%$ of FWW); ash, protein, and lipid content ( $\%$ of dry weight, DW, mean \pm $\mathrm{SE})$; and energy content $\left(\mathrm{kJ} \mathrm{g}^{-1} \mathrm{DW}\right.$; mean $\left.\pm \mathrm{SE}\right)$. ( ) Values obtained by bomb calorimetry; (O) estimates based on protein and lipid content. SE of replicate measurements (sample sizes given in 'Methods' section) are too small to be seen in most cases 
length is correlated negatively with protein content $(\mathrm{r}=-0.954, \mathrm{p}=0.006)$ and positively with ash content $(r=0.846, p=0.038)$. Another significant correlation is between ash and protein content $(r=-0.829, p=0.042$, all significance levels 1 -tailed). The largest fish (a shallow GTP male that had settled in a 3 to $6 \mathrm{~m}$ territory about 1 mo before capture) showed a relatively high ash and low protein content and its energy content was below average. The $26 \mathrm{~cm}$ IP fish (a sexually active female from a 3 to $6 \mathrm{~m}$ territory) showed the highest gonadosomatic index, fat content and energy content. Relative gonad size shows a clear increase with size between 13 and $26 \mathrm{~cm}$. The $13 \mathrm{~cm}$ JU (no growth measured) and the 19 and $20 \mathrm{~cm}$ IP fish had relatively high protein contents and intermediate energy contents. The energy contents calculated from body composition are slightly higher (difference: 0.4 to $1.2 \mathrm{~kJ} \mathrm{~g}^{-1} \mathrm{DW}$ ) than those measured directly (paired $t$-test: $t_{4}=6.86$, $\mathrm{p}=0.002)$.

Growth efficiency is highest for protein (up to $56 \%$ of intake and up to $84 \%$ of assimilation) and much lower when the turnover of energy $(<7.9$ and $11.3 \%$ respectively) and AFDW $(<6.3$ and $14 \%$ respectively) are considered (Table 2). Daily food intake and assimilation was lower on the shallow reef than on the deeper reef. Growth of JU and IP females has been assumed to be equal in both zones, while shallow GTP males grow faster than TTP males. Therefore, the growth efficiencies are considerably higher for fish residing in groups on the shallow reef than for fish in territories on the deeper reef, especially when both TP categories are compared. Finally, growth efficiency clearly decreases with increasing size, except for the higher efficiency of $40 \mathrm{~cm}$ GTP males compared to $30 \mathrm{~cm}$ GIP fish.

\section{DISCUSSION}

\section{Growth in a life history context}

Predation pressure is usually much higher on small juveniles than on larger fish (Wootton 1990). Therefore, fast growth seems a good strategy to escape predation. Because juveniles do not partake in reproduction, they can channel all surplus energy into growth. An indication that growth is traded off against reproductive effort is the negative correlation between growth and spawning rate of TTP males. However, since food quality and availability may vary between territories, this finding yields no definitive proof. The most direct evidence of a trade-off between growth and reproduction is provided by the differences between GTP and TTP males. Because the latter acquire and assimilate larger amounts of food, their lower growth rates cannot be ascribed to lower food

Table 2. Sparisoma viride. Daily food intake, assimilation and gross growth efficiencies ( $K_{1}$ and $K_{2}$ relative to food intake and assimilation respectively), calculated for a $10 \mathrm{~cm}$ juvenile (JU, a 20 and $30 \mathrm{~cm}$ initial phase (IP) fish, and for a $40 \mathrm{~cm}$ terminal phase (TP) male. Separate estimates for the shallow reef $(<3.5 \mathrm{~m}$ JU, group initial phase fish (GIP) and group terminal phase males (GTP)] and for the deeper reef [> $3.5 \mathrm{~m}$; JU, territorial initial phase fish (TIP) and territorial terminal phase males (TTP)]. Food intake and assimilation data from Table 7 in Bruggemann et al. (1994b)

\begin{tabular}{|c|c|c|c|c|c|c|c|c|}
\hline \multirow[t]{3}{*}{ Category } & \multicolumn{2}{|c|}{$\mathrm{JU} 10 \mathrm{~cm}$} & \multicolumn{2}{|c|}{ IP $20 \mathrm{~cm}$} & \multicolumn{2}{|c|}{ IP $30 \mathrm{~cm}$} & \multicolumn{2}{|c|}{ TP $40 \mathrm{~cm}$} \\
\hline & $<3.5 \mathrm{~m}$ & $>3.5 \mathrm{~m}$ & GIP & TIP & GIP & TIP & GTP & TTP \\
\hline & & & & & & & & \\
\hline \multicolumn{9}{|l|}{ Daily food intake } \\
\hline AFDW $(\mathrm{g})$ & 0.56 & 0.94 & 5.35 & 7.35 & 15.37 & 21.36 & 22.96 & 31.73 \\
\hline Protein (g) & 0.06 & 0.11 & 0.51 & 0.75 & 1.32 & 2.08 & 1.88 & 2.77 \\
\hline Energy (kJ) & 10 & 17 & 103 & 139 & 307 & 418 & 448 & 617 \\
\hline \multicolumn{9}{|l|}{$K_{1}(\%)$} \\
\hline AFDW & 6.25 & 3.72 & 2.55 & 1.86 & 0.10 & 0.07 & 0.34 & 0.01 \\
\hline Protein & 56.00 & 30.55 & 25.53 & 17.36 & 1.07 & 0.68 & 3.70 & 0.12 \\
\hline Energy & 7.89 & 4.64 & 2.94 & 2.18 & 0.12 & 0.09 & 0.40 & 0.01 \\
\hline \multicolumn{9}{|l|}{ Daily assimilation } \\
\hline AFDW (g) & 0.25 & 0.42 & 1.25 & 4.36 & 3.59 & 12.71 & 5.38 & 18.91 \\
\hline Protein (g) & 0.04 & 0.07 & 0.32 & 0.57 & 0.86 & 1.57 & 1.24 & 2.28 \\
\hline Energy (kJ) & 7 & 13 & 44 & 104 & 130 & 314 & 197 & 474 \\
\hline \multicolumn{9}{|l|}{$K_{2}(\%)$} \\
\hline AFDW & 14.00 & 8.33 & 10.92 & 3.13 & 0.44 & 0.13 & 1.46 & 0.02 \\
\hline Protein & 84.00 & 48.00 & 40.69 & 22.84 & 1.64 & 0.90 & 5.61 & 0.14 \\
\hline Energy & 11.27 & 6.07 & 6.87 & 2.91 & 0.29 & 0.12 & 0.90 & 0.02 \\
\hline
\end{tabular}


abundance and must be related to a higher investment in reproduction and territory defence. Although territorial behaviour may also be related to the defence of food or mates (van Rooij et al. unpubl.), it ultimately guarantees the TTP males a high spawning success. Therefore, any investment in territory defence may also be regarded as an investment in reproduction.

Sexually active females can be expected to invest more energy in gamete production than males, since the production of eggs is energetically more expensive than that of sperm (Wootton 1985). The relative gonad weight of the largest dissected female was over 4 times that of the TP male and almost twice as heavy in absolute weight. Still, a GSI of $0.22 \%$ seems quite low compared to the 2 to $30 \%$ values commonly found for ripe females of many other species (including both daily and seasonal spawners; Wootton 1990). However, ovary weight may strongly depend on the number of eggs present and, hence, on the time since last spawning (Colin \& Clavijo 1988, Koltes 1993). Our female was caught about $1 \mathrm{~h}$ after the spawning period. Egg collections in the field show that females may release up to 10000 eggs in a single spawning (J. M. van Rooij unpubl.). Clearly, the GSI is not a good indicator of female reproductive effort, which should include the number of eggs produced daily. The relatively steep decrease in growth rate with increasing size observed for IP females may be caused by the fact that larger females produce larger numbers of eggs relative to body weight, as also indicated by the allometric ovary growth of Sparisoma viride at Grand Turk (Koltes 1993). However, despite their large investment in eggs, average growth of females (adjusted for size) does not seem to be lower than that of TTP males. This suggests that males invest relatively more energy in behaviour related to reproduction (like mate acquisition and territory defence). Time budget data (J. M. van Rooij unpubl.) show that during the daily spawning period, IP females show reduced grazing rates for brief ( $<5 \mathrm{~min}$ ) periods only, whereas TTP males hardly graze for periods up to an hour. Furthermore, TTP males were shown to undertake more and longer aggressive acts against conspecifics throughout the day than IP or GTP fish (van Rooij et al. unpubl.).

The fast growth of GTP males provides an explanation for the abundance of bachelor males. This is best illustrated by a plot of predicted weight versus age for the different categories, as shown in Fig. 5. These predictions are derived from the integral forms of the growth equations given in Table 1. The IP and GTP growth curves were positioned to start where the JU curve ends, at a size of $200 \mathrm{~g}$ or $218 \mathrm{~mm}$. Likewise, the TTP curve starts from the GTP curve at a size of $310 \mathrm{~mm}$ or $606 \mathrm{~g}$, the minimum size found for TTP

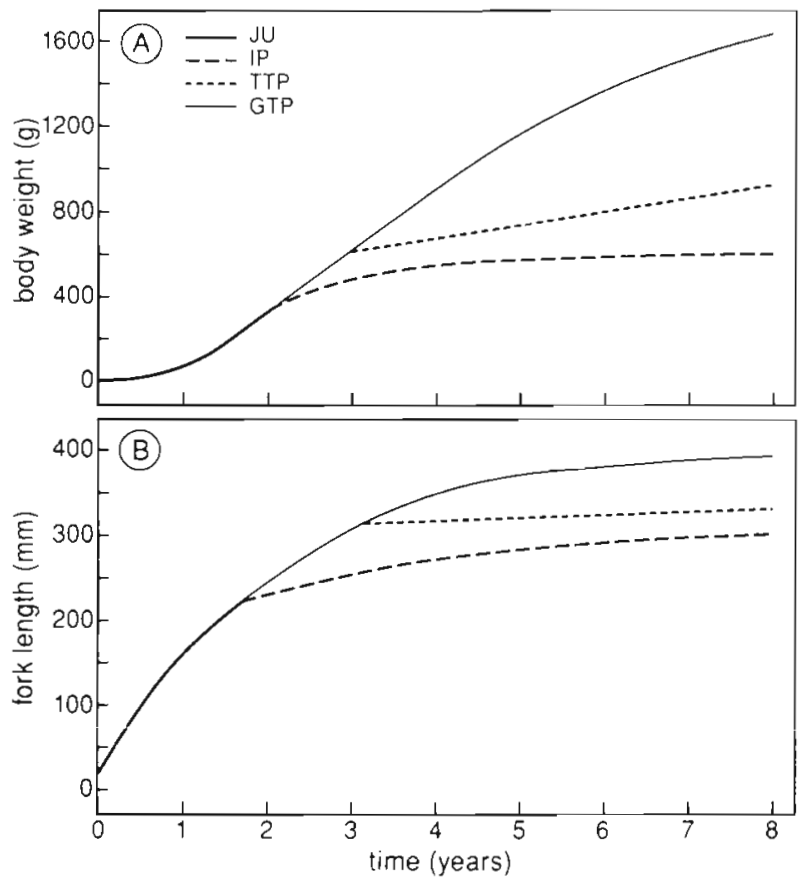

Fig. 5. Sparisoma viride. Plots of (A) predicted weight and (B) predicted fork length vs age for juveniles [JU, including initial phase (IP) fish < $200 \mathrm{~g}$ ] and the 3 adult categories (IP, group and territorial terminal phase (GTP and TTP) males]. Predictions calculated from (the integral forms of) equations given in Table 1

males (van Rooij et al. unpubl.). Fig. 5 shows that IP fish never reach this size. In order to grow large enough to become a TTP male, they have to go through a GTP phase. However, this alone does not explain why so many fish change sex at sizes even smaller than 25 to $30 \mathrm{~cm}$. If we compare the age of a $30 \mathrm{~cm}(547 \mathrm{~g}) \mathrm{IP}$ fish with that of an individual that changed sex at $218 \mathrm{~mm}$ (200 g), a difference is found varying from 1.3 to $5 \mathrm{yr}$ (according to the weight and length predictions respectively). The differences are caused by the different asymptotic sizes predicted by the length and the weight models (see Ricker 1979 for a discussion of asymptotic size estimates). In any case, a fish that changes sex at about $22 \mathrm{~cm}$ FL may acquire the territorial male status 1.3 to $5 \mathrm{yr}$ sooner The loss in reproductive output, accrued during the $1.2 \mathrm{yr}$ that it takes a bachelor to grow from 22 to $30 \mathrm{~cm}$, can be compensated in a few months, considering the 5 times higher average spawning rate of TTP males compared to fernales (van Rooij et al. unpubl.). Although insight in the mortality schemes of IP and TP fish is required to compare the lifetime reproductive success of different strategies (Stearns 1992), our data suggest that bachelor males may indeed do as well as fish that change sex later. They 
seem to follow an alternative life history tactic, sacrificing current for future reproductive success by trading off reproduction for growth.

\section{Growth in a trophodynamic context}

Russ \& St John (1988) compared the growth of scarids and other reef fish, using a 'growth performance' index $(\psi)$, proposed by Munro \& Williams (1985): $\psi=\log (K)+0.67 \times \log \left(W_{\infty}\right) ;$ in which $K$ and $W_{\infty}$ are the parameters in the VBG equation $(K=365 \times a / 3$; the factor 365 to convert daily to yearly rate). This index is introduced to circumvent the interdependence between $K$ and asymptotic size, since small fish tend to have higher $K$-values than related larger ones (Munro \& Williams 1985, see also Buesa 1987). $\psi$ ranges from 1.53 to 2.01, both for Caribbean and for Pacific scarids, and compares favourably with that of non-herbivorous reef fish (some serranids, haemulids, a lutjanid, balistid and siganid). Calculated from our parameter estimates for weight-growth, we find a $\psi$ of 2.42 for $\mathrm{JU}$ fish, 1.88 for IP fish, 1.17 for TTP males and 1.75 for GTP males. Russ \& St John (1988) report a $\psi$ of 1.82 for Sparisoma viride. Although based on the growth of only 3 tagged IP fish measured by Randall (1962) in the Virgin Islands, this value compares well to our estimate. Our data thus seem to confirm Russ \& St John's (1988) suggestion that scarids grow relatively fast, despite their poor quality diet, low in protein content and containing indigestible carbohydrates like cellulose (Montgomery \& Gerking 1980, Horn 1989). It has been suggested that the high standing stocks and growth rates of herbivorous fish can only be maintained by a non-algal, protein rich diet component, such as attached microorganisms (Pandian \& Vivekanandan 1985). We observed JU $S$. viride in aquaria to prey upon small planktonic crustaceans when these were offered, and Bruggemann et al. (1994a) mention the presence of invertebrate remains in the faeces of $\mathrm{fish}<10 \mathrm{~cm}$. Bellwood (1988) reports that recently settled Pacific scarids have a mainly carnivorous diet. The seawater used in our JU growth experiments was not filtered, and the coral rubble offered as grazing substrate was not checked for animal life, so it is quite possible that the JU diets were not strictly herbivorous. Bruggemann et al. (1994a) determined the nutritional value of $S$. viride's diet from analyses of algae, scraped off from natural pieces of substrate, which did not contain any visible animal component. Therefore, it is quite possible that food intake and assimilation of the $10 \mathrm{~cm} \mathrm{JU}$ have been underestimated and growth efficiency overestimated. Brett \& Groves (1979) conclude (from the limited data available) that gross energy conversion in young herbivorous fish is not likely to exceed $20 \%$, while values up to $50 \%$ can be achieved by carnivorous juveniles. Our estimate of 4.6 to $7.9 \%$ for a $10 \mathrm{~cm}$ fish does not seem so high as to require a carnivorous diet. When protein conversion is considered, the 31 to $56 \%$ grass efficiency compares rather well with the 43 to $50 \%$ values found by Fris \& Horn (1993) for juveniles of a temperate zone herbivore, raised on a strict seaweed diet. Polunin \& Brothers (1988) report gross efficiencies of $0.2 \%$ for $\mathrm{C}$ and $0.5 \%$ for $\mathrm{N}$ in adults of a pomacentrid on a Papua New Guinea coral reef. The only other value known for coral reef herbivores is the $<1 \%$ gross growth efficiency (for C) mentioned in Polunin \& Klumpp (1992, reference to unpubl. data) for adults of a larger pomacentrid and 2 scarid species. These values compare quite well with those of the largest and sexually active adult $S$. viride (IP $30 \mathrm{~cm}$ and TTP $40 \mathrm{~cm} F L$ ) found here. However, JU fish, smaller IP fish, and sexually inactive TP males attain much higher efficiencies. Since the latter categories form a significant part of the total population (van Rooij et al. unpubl.), the total somatic production of our $S$. viride population is much higher than that which would have been predicted from the growth of sexually active adults alone.

In addition to these differences between social categories and life phases, we also investigated intrapopulation variation due to possible effects of depth of the home range, season and the condition of fish. A significant effect of depth on growth could not be detected, but the trend that emerges from our data agrees with that described for condition. TTP males seem to do better at greater depths, which may be explained by the increase of high yield food patches with depth, as found by Bruggemann et al. (1994a). IP fish, however, tend to grow faster in the shallower zones, which would not be expected from the lower food intake and assimilation on the shallow reef. This can be explained by a higher abundance of sexually inactive IP fish in the shallowest reef parts, since these fish are probably excluded from territories (van Rooij et al. unpubl.).

All adult categories showed the highest growth rates in the warmest season (August to October), when they also tended to be in the best condition (van Rooij et al. 1995). Although fish in better condition can be expected to grow faster, the low $\mathrm{R}^{2}$ values for the correlation between the growth residuals and the condition indices of IP and GTP fish indicate that growth and (changes in) condition are largely independent. This is further confirmed by the finding that growth was not lowest when the fish are in the poorest condition (May to July). Although spawning occurred all year round (van Rooij et al. unpubl.), we cannot exclude the possibility that reproductive effort (e.g. the daily number of eggs spawned) fluctuates seasonally. However, this 
would still not explain the seasonal changes in growth of GTP males, since these fish hardly spawn at all. Possible causes for a seasonal growth pattern, besides temperature, are variations in food availability or quality, which deserve further investigation.

Acknowledgements. We thank the Bonaire Marine Park authorities for permission to work at Bonaire's protected reefs and for working facilities at Karpata Ecological Centre. We also thank Roberto Hensen (Fundashon Marcultura) and Edward Berben (Dept of Agriculture and Fisheries) for their logistic support, Jerry Schnabel, Michael Teitel and Teun Mateus for their vital contribution to the successful use of stereo photography, and 2 anonymous reviewers for their helpful comments. J.v.R. and J.H.B. were funded by the Netherlands Foundation for the Advancement of Tropical Research (WOTRO, grants W88-137 and W84-280), whose support is gratefully acknowledged.

\section{LITERATURE CITED}

Bellwood DR (1988) Ontogenetic changes in the diet of early post-settlement Scarus species (Pisces: Scaridae). J Fish Biol 33:213-219

Brett JR, Groves TDD (1979) Physiological energetics. In: Hoar WS, Randall DJ, Brett SR (eds) Fish physiology, Vol 8. Bioenergetics and growth. Academic Press, Orlando, $p$ $279-352$

Bruggemann JH, van Oppen MJH, Breeman AM (1994a) Foraging by the stoplight parrotfish Sparisoma viride. I. Food selection in different, socially determined habitats. Mar Ecol Prog Ser 106:41-55

Bruggemann $\mathrm{JH}$, Begeman J, Bosma EM, Verburg P, Breeman AM (1994b) Foraging by the stoplight parrotfish Sparisoma viride. II. Intake and assimilation of food, protein, and energy. Mar Ecol Prog Ser 106:57-71

Buesa RJ (1987) Growth rate of tropical demersal fishes. Mar Ecol Prog Ser 36:191-199

Choat JH (1991) The biology of herbivorous fishes on coral reefs. In: Sale PF (ed) The ecology of fishes on coral reefs. Academic Press, London, p 120-155

Clarke RD (1992) Effects of microhabitat and metabolic rate on food intake, growth and fecundity of two competing coral reef fishes. Coral Reefs 11:199-205

Colin PL, Clavijo I (1988) Spawning activity of fishes producing pelagic eggs on a shelf edge coral reef, Southwestern Puerto Rico. Bull mar Sci 43:249-279

Elliott JM (1976) Body composition of brown trout (Salmo trutta L.) in relation to temperature and ration size. J Anim Ecol 45:273-289

Fris MB, Horn MH (1993) Effects of diets of different protein content on food consumption, gut retention, protein conversion, and growth of Cebidichthys violaceus (Girard), an herbivorous fish of temperate zone marine waters. J exp mar Biol Ecol 166:185-202

Gladstone W, Westoby M (1988) Growth and reproduction in Canthigaster valentini (Pisces, Tetraodontidae): a comparison of a toxic reef fish with other reef fishes. Environ Biol Fish 21:207-221

Horn MH (1989) Biology of marine herbivorous fishes. Oceanogr mar Biol A. Rev 27:167-272

Jones GP (1986) Food availability affects growth in a coral reef fish. Oecologia 70:136-139
Koltes KH (1993) Aspects of the reproductive biology and social structure of the stoplight parrotfish Sparisoma viride, at Grand Turk, Turks and Caicos Islands, B.W.1. Bull mar Sci 52:792-805

Montgomery WL, Gerking SD (1980) Marine macroalgae as food for fish: an evaluation of potential food quality. Environ Biol Fish 5:143-153

Munro JL, Williams DMcB (1985) Assessment and management of coral reef fisheries: biological, environmental and socio-economic aspects. Proc 5th int Coral Reef Congr 4: $544-581$

Paine RT (1966) Endothermy in bomb calorimetry. Limnol Oceanogr 11:126-129

Pandian TJ, Vivekanandan E (1985) Energetics of feeding and digestion. In: Tytler P, Calow P (eds) Fish energetics: new perspectives. Croom Helm, London, p 99-124

Polovina JJ (1984) Model of a coral reef ecosystem I. The ECOPATH model and its application to French Frigate Shoals. Coral Reefs 3:1-11

Polunin NVC, Brothers EB (1988) Low efficiency of dietary carbon and nitrogen conversion to growth in an herbivorous coral-reef fish in the wild. J Fish Biol 35:869-879

Polunin NVC, Klumpp DW (1992) A trophodynamic modei of fish production on a windward reef tract. In: John DM, Hawkins SJ, Price JH (eds) Plant-animal interactions in the marine benthos. Oxford University Press, Oxford, p $213-233$

Prus ' 1 (1975) Calorimetry and body composition. in : Grocicinski W. Klekowski RZ, Duncan A (eds) Methods for ecological bioenergetics. IBP handbook no 24. Blackwell Scientific Publications, Oxford, p 149-160

Randall JE (1962) Tagging reef fishes in the Virgin Islands. Proc Gulf Caribb Fish Inst 14:201-241

Reinboth, R (1968) Protogynie bei Papageifischen (Scaridae). Z Naturf 23b:852-855

Ricker WE (1979) Growth rates and models. In: Hoar WS, Randall DJ, Brett SR (eds) Fish physiology, Vol 8. Bioenergetics and growth. Academic Press, Orlando, $p$ $677-743$

Ricker WE (1984) Computation and uses of central trend lines. Can J Zool 62:1897-1905

Russ GR, St John J (1988) Diets, growth rates and secondary production of herbivorous coral reef fishes. Proc 6 th int Symp Coral Reefs 2:37-43

Schultz ET, Warner RR (1989) Phenotypic plasticity in lifehistory traits of female Thalassoma bifasciatum (Pisces: Labridae). 1. Manipulations of social structure in tests for adaptive shifts of life-history allocations. Evolution 43: $1497-1506$

Schultz ET, Warner RR (1991) Phenotypic plasticity in lifehistory traits of female Thalassoma bifasciatum (Pisces: Labridae). 2. Correlation of fecundity and growth rate in comparative studies. Environ Biol Fish 30:333-344

Sokal RR, Rohlf FJ, (1981) Biometry, 2nd edn. WH Freeman and $\mathrm{Co}$, New York

Stearns SC (1992) The evolution of life histories. Oxford University Press, Oxford

Thresher RE (1983) Habitat effects on reproductive success in the coral reef fish. Acanthochromis polyacanthus (Pomacentridae). Ecology 64:1184-1199

van Rooij JM, Videler JJ (1995) A simple method to correct for bias in stereo-photographic length measurements of freeswimming reef fish. J exp mar Biol Ecol (in press)

van Rooij JM, Bruggemann JH, Videler JJ, Breeman AM (1995) Ontogenetic, social, spatial and seasonal variations in condition of the reef herbivore Sparisoma viride. Mar Biol (in press) 
Warner RR (1984) Deferred reproduction as a response to sexual selection in a coral reef fish: a test of the life historical consequences. Evolution 38:148-162

Warner RR (1991) The use of phenotypic plasticity in coral reef fishes as tests of theory in evolutionary ecology. In: Sale PF (ed) The ecology of fishes on coral reefs. Academic Press, London, p 387-398

Warner RR, Downs IF (1977) Comparative life histories: growth vs reproduction in normal males and sex-changing

This article was submitted to the editor hermaphrodites of the striped parrotfish, Scarus croicensis. Proc 3rd int Symp Coral Reefs 1:275-281

Weatherly AH, Gill HS (1987) The biology of fish growth. Academic Press, London

Wootton RJ (1985) Energetics of reproduction. In: Tytler P. Calow P (eds) Fish energetics: new perspectives. Croom Helm, London, p 231-254

Wootton RJ (1990) Ecology of teleost fishes. Chapman \& Hall, London

Manuscript first received: December 30, 1994

Revised version accepted: February 14, 1995 